\title{
Invited review: Examining farmers' personalities and attitudes as possible risk factors for dairy cattle health, welfare, productivity, and farm management: A systematic scoping review
}

\author{
F. Adler, ${ }^{1 *}$ R. Christley, ${ }^{2}$ and A. Campe ${ }^{1}$ \\ ${ }^{1}$ Department of Biometry, Epidemiology and Information Processing, WHO Collaborating Centre for Research and Training for Health \\ at the Human-Animal-Environment Interface, Buenteweg 2, D-30559 Hannover, Germany \\ ${ }^{2}$ Institute of Infection and Global Health, University of Liverpool, Liverpool L69 3BX, United Kingdom
}

\begin{abstract}
We aimed to determine how research regarding farmers' personalities and attitudes as risk factors is reported (methodological approaches to assessing, extracting, and processing data and analyzing risk factors) and to explore evidence for the effect of farmers' attitudes and personalities on dairy cattle health, welfare, productivity, and management. Therefore, we conducted a systematic review of studies on personality and attitude as risk factors for dairy cattle health, welfare, productivity, and farm management. Database searches captured 1,144 records, and 38 were finally included in the review. Thirty-three manuscripts assessed farmers' attitudes, 1 assessed their personalities, and 4 assessed both as risk factors. These potential risk factors were checked for relationships with more than 50 different outcome variables regarding farm management (17 manuscripts), animal health (13 manuscripts), animal productivity (11 manuscripts), and animal welfare (4 manuscripts). The approaches to assessing risk factors and processing and interpreting data varied greatly; thus, drawing conclusions regarding the effects of attitude and personality as risk factors is impeded because manuscripts are difficult to compare. Our findings highlight the need for harmonization of attitudes and personality assessments in future research. Furthermore, researchers should carefully consider which depth of detail to apply when planning and evaluating related research. Nevertheless, results highlight the importance of the effect of personality and attitude on outcomes. Farmers' personality and attitudes are associated with dairy cattle health, welfare, productivity, and management. In general, attitudes indicating higher degrees of technical knowledge, affection with problems, perceived responsibility, perception of control of a situation, a
\end{abstract}

Received May 9, 2018.

Accepted December 24, 2018.

*Corresponding author: friedemann.adler@tiho-hannover.de better human-animal relationship, or a positive evaluation of the benefits of management decisions tended to affect outcomes in a beneficial way. "Agreeableness" and "conscientiousness" were shown to promote better farm performance, whereas "neuroticism" had a negative effect. Therefore, further research on attitude and personality and their consideration by professionals and decision-makers within the dairy sector and politics is strongly recommended. This might provide the chance to better understand the needs of dairy farmers and therefore develop tailored advice and support strategies to improve both satisfactory and constructive cooperation.

Key words: dairy, attitude, personality, risk factor

\section{INTRODUCTION}

Good stockmanship is necessary for optimization of health, welfare, husbandry, and management, thereby affecting physical and financial performance in animal production (Beynon, 1991). This influence on animal performance in general can occur indirectly by management decisions determining the conditions under which animals live or directly through a certain human-animal relationship (HAR), which M. F. Seabrook reported in 1972 when investigating the cowmans' effect on milk yield in dairy cattle (Seabrook, 1972). The investigation of human-animal interactions has subsequently led to the construction of new concepts such as the HAR to describe the effects of humans on animals as a part of animal welfare studies. The HAR has become one of the most widely used concepts with respect to explaining human influence on animal welfare. It is based on the assumption that animals fear humans (Hemsworth, 2003). The level of fear in farmed animals has been shown to affect their performance for various species (Hemsworth et al., 1981; Barnett et al., 1992; Cransberg et al., 2000; Hemsworth et al., 2000). It has also been shown that the way stockpersons interact with their animals has strong effects on the level of stress 
and fear animals experience (Hemsworth et al., 1989; Jones, 1993). Today, stockmanship, in general, is proposed to consist of 3 essential traits: animal husbandry knowledge, animal husbandry skills, and personal qualities (Department for Environment, Farming and Rural Affairs, 2007). The fact that personal qualities are seen as a main trait of stockmanship is a result of researchers, in addition to the investigation of environmental risk factors, paying increasing attention to the farmers or stockpersons themselves regarding their influence on farm animal well-being and performance (Beynon, 1991). Hence, it is important to understand which person-intrinsic determinants might lead to farmers deciding or acting in a certain way; socio-psychological approaches have therefore emerged in veterinary and animal science research. These approaches assess human-intrinsic influences, including personal qualities. However, within this research, diverse terms have been used to characterize these personal qualities of interest: "personal characteristics" (Waiblinger et al., 2002), "ethical positions" (de Rooij et al., 2010), "empathy" (Kielland et al., 2010), "perceptions" (Vaarst and Sorensen, 2009), "mindset" (Scherpenzeel et al., 2016), "attitude" (Bruijnis et al., 2013), and "personality" (Hanna et al., 2009). This diversity reflects underlying variation, including

- use of different approaches to capture the stockmen's personal qualities,

- different theoretical backgrounds underpinning exploration of the concepts of farmer-intrinsic risk factors, and

- knowledge of assessment methods and results interpretation are required to evaluate the significance of the findings and the importance of stockman-intrinsic risk factors.

Existing literature revealed that the psychological concepts "personality" and "attitude" were consistently used to label personal qualities. Several socio-psychological research publications were available regarding these concepts' theoretical backgrounds. In preparing for a nationwide cross-sectional study on dairy herd health and performance, we therefore focused on these 2 concepts to investigate how they affect dairy cattle health, welfare, productivity, and farm management.

Before assessing the effect of attitude and personality on these outcome themes, it is important to define and describe the theoretical backgrounds of these concepts:

Personality refers to individual differences in characteristic patterns of thinking, feeling, and behaving (Ashton, 2013). Personality psychology is "the study of what makes a person unique from others" (Feist, 1998). In contrast to attitude measures, which are context de- pendent (Schwarz and Bohner, 2001), personality traits remain relatively stable after a person reaches age 30 (Costa and McCrae, 1994). Psychologists capture human personality in predefined domains, which have been characterized in lexical studies, which identify the most salient aspects of human personality based on these aspect's representation in a language's lexicon (Saucier and Goldberg, 2001). The names and numbers of domains and subordinate facets finally representing human personality differ depending on the framework considered. For example, the Big Five framework is popular and is the most widely used and extensively researched personality model. This framework classifies individual personality differences into 5 broad empirically derived domains (Gosling et al., 2003). Each domain includes 6 subordinate facets.

In contrast to the Big Five framework, other researchers argue that a 6-factor structure better describes personality variations (de Vries et al., 2016); thus, the HEXACO model (honesty-humility, emotionality, extraversion, agreeableness, conscientiousness, and openness to experience) was developed. However, regardless of the overall number of domains and facets included in a framework, psychologists have shown that personality dimensions can predict human behaviors such as health behavior (Booth-Kewley and Vickers, 1994). Irrespective of the framework considered, approaches to assessments are the same; respondents are provided with several descriptive statements to rate on a Likert scale in most validated inventories.

Attitude, however, represents a summary evaluation of a psychological object (Ajzen and Fishbein, 2000). Psychological objects are the objects that psychologists choose to investigate (Danziger, 1993). This expression is therefore used synonymously for "attitude object" here. Every attitude must be related to one specific psychological object (Ajzen, 2001). In assessing attitude, psychological objects can be physical objects (e.g., dairy cows), theoretical questions (e.g., importance of calf-rearing practices), or behavioral options (e.g., adopting certain farm management practices). Assessment of a person's attitude toward an object requires that the object is presented to that person for evaluation. This can be done by direct and indirect measurement. A common approach to direct measurement is to provide the respondent with statements related to the attitude object. The respondent would then agree or disagree with that statement using a Likert or semantic differential scale. Indirect measurements use projective techniques, presenting the person with ambiguous or incomplete stimuli (e.g., pictures or open-ended qualitative interview questions) that require interpretation or lead to narrative material around the psychological object of interest. The person's attitude is then inferred 
by how they respond (McLeod, 2009). In both direct and indirect measurement, the researcher must extract and interpret the attitude information by applying suitable data processing and analysis techniques.

Attitude is an important research area because attitudes can predict behavior (Ajzen, 2001). Two prominent theoretical frameworks underpinning this are the Theory of Reasoned Action and the Theory of Planned Behavior (Ajzen, 1985; Kauppinen et al., 2013). However, another important aspect is that attitudes can change; motivation and capacity are assumed to be required for such a change (Wilson et al., 2000). Farmers' attitudes, therefore, are potential targets for external stimuli (e.g., veterinary consultancy, intervention programs) aiming to change behavior to improve the animals' situation or farm productivity. For example, the positive effect of a cognitive behavioral intervention program on attitude and behavior of dairy stockpersons has been reported by Hemsworth et al. (2002).

To investigate the effect of personality and attitudes on dairy cattle health, welfare, productivity, and farm management, we conducted a systematic scoping review of the related literature. In contrast to systematic reviews seeking to appraise and synthesis research evidence, scoping reviews aim to assess and identify the scope and nature of research related to a specific topic (Grant and Booth, 2009). The review was conducted focusing on 3 objectives:

(1) Describe the spectrum of studies on personality and attitude as risk factors for dairy cattle health, welfare, productivity, and farm management.

(2) Describe whether risk factors (personality and attitude) are related to (which) dependent variables.

(3) Examine whether overall contextual conclusions can be drawn on the effect of farmers' attitudes and personalities on dairy cattle health, welfare, productivity, and management.

\section{MATERIALS AND METHODS}

Based on PRISMA statement recommendations (Liberati et al., 2009) and guidelines proposed for conducting scoping reviews (Colquhoun et al., 2014; Peters et al., 2015), the existing literature was systematically reviewed to provide a structured overview of research on farmers' personalities and attitudes as risk factors for dairy cattle health, welfare, productivity, and management. The review was focused only on the risk factor analyses that consider personality or attitude (or both) as (human) risk factors for an outcome related to animal health, welfare, productivity, and manage- ment conditions. Welfare is a multidimensional term including an animals' physical and mental state defined by the "five freedoms" (Department for Environment, Farming and Rural Affairs, 2007). From this perspective it might also cover aspects related to other thematic areas of dependent variables (i.e., health, productivity). Nevertheless, for this review, it was decided to consider "health" and "productivity" as independent thematic areas for the purpose of clear discrimination and to be able to define eligibility criteria (see below). We did not perform a meta-analysis due to the wide scope of our approach. Furthermore, we did not focus on intervention strategies associated with personality and attitude; this would be a useful second step after identification of the role of personality and attitude traits as risk factors. Instead, we describe the scope of research and general findings and present aspects related to methodological approaches and results presentation and interpretation that may be considered in future research.

\section{Search and Extraction Strategy}

Eligibility criteria were defined before the study. The review includes peer-reviewed journal articles on dairy cattle of all breeds and ages. Languages were limited to English and German. Geography and publication year were not restricted. Personality or attitude had to be explicitly mentioned in the title, abstract, or key words and had to be reported as risk factors for one or more dependent outcomes of interest. Specifically, dependent variables had to be related to animal health (e.g., disease prevalence, SCC), productivity (e.g., milk yield, milk contents), farm management (e.g., on-farm management decisions and farmers' behaviors toward animals), and welfare. Welfare in the context of this review covers the animals' mental state (e.g., aversive behavior indicating stress). Assessments had to be performed by clinical examination or scoring the animals or evaluation of their behavior, the farmers' behavior, farm-performance data, data collected by the farmers on the farm, pre-existing data from external sources (e.g., health monitoring programs), or assessing information from questionnaires or interviews.

Web of Science (http://apps.webofknowledge.com), PubMed (https://www.ncbi.nlm.nih.gov/pubmed/), and $\mathrm{CAB}$ Abstracts (http://ovidsp.tx.ovid.com/sp-3 $.32 .2 \mathrm{a} /$ ovidweb.cgi) were used as search databases. Searches were performed in German and English.

The search strategy was identical for all 3 databases. Known relevant literature was used to develop search strings. Sensitivity analysis was performed by testing different combinations of concepts and key words in all 3 databases. Concepts were modified by the outcome to make sure all relevant literature was captured. Terms 
Table 1. Concepts and keywords operated in the final database search in English ${ }^{1}$

\begin{tabular}{|c|c|c|c|c|}
\hline Concept 1 & Concept 2 & Concept 3 & Concept 4 & Concept 5 \\
\hline $\begin{array}{l}\text { farmer* } \\
\text { stockperson* } \\
\text { stockman* } \\
\text { herdsman/herdsmen } \\
\text { producer* } \\
\text { rancher* } \\
\text { smallholder* }\end{array}$ & $\begin{array}{l}\text { personalit* } \\
\text { "personal characteristics" } \\
\text { attitude* }\end{array}$ & $\begin{array}{l}\text { welfare } \\
\text { wellbeing } \\
\text { productivity } \\
\text { health* } \\
\text { management } \\
\text { performance }\end{array}$ & $\begin{array}{l}\text { dairy } \\
\text { cow* } \\
\text { cattle } \\
\text { calve* } \\
\text { heifer* }\end{array}$ & $\begin{array}{l}\text { relation* } \\
\text { associat* } \\
\text { correlation* } \\
\text { influence* } \\
\text { effect* }\end{array}$ \\
\hline
\end{tabular}

${ }^{1}$ Columns are linked with Boolean AND operators. Rows are linked with Boolean OR operators. * indicates a wildcard operator allowing any number of additional letters. Words in quotation marks are regarded as connected terms.

which did not contribute to improvement of the queries were dismissed. For example, terms included in explorative searches such as "cowman" and "animal-keeper" (concept I) and "trait*" (concept II) were removed because they did not improve search performance.

Tables 1 and 2 indicate the final search concepts and key words included in the search strings. The final search in English was conducted on April 24, 2017 (Web of Science, PubMed, and CAB Abstracts from 1989) and on May 10, 2017, for CAB Abstracts 1910-1989. The final search in German was conducted on May 10, 2017 , in all 3 databases. By the end of the revision process, an update was performed running the search in all 3 databases once more on December 5, 2018.

Study selection was performed in 3 stages. First, the title, abstract, and key words from the papers captured by the final database searches were screened. The terms "personality" or "attitude" or both had to be explicitly mentioned and considered potential influencing factors. Outcome variables had to be related to dairy cattle health, welfare, productivity, or farm management. Second, after removing duplicates, full texts were then checked for relevance in detail. Finally, reference lists of the eligible papers were checked for potential missing records.

We developed an a priori data sheet to extract information from the included full texts, using Microsoft Excel (Microsoft Corp., Redmond, WA). The sheet was piloted by the first author on 5 randomly selected included papers and refined accordingly until the data sheet captured all pertinent information relating to the review's objectives. To prevent observer bias, data were extracted independently and in duplicate by the first author and 2 colleagues. Differences in extracted information were discussed by involving the last author to reach consensus.

\section{Extracted Information}

The final data sheet consisted of 22 items. Three were included to internally manage data ["consecutive number of the record," "record included in data extraction" (yes or no), and "record's citation"].

To describe the study spectra on personality and attitude as risk factors, descriptive characteristics of the published research were extracted: "country of research," "personality assessed" (yes or no), "attitude assessed" (yes or no), and "dependent variables assessed." Per the predefined dependent variable categories, the "dependent variable category" (health, welfare, productivity, or management) was extracted. Whether the "theoretical framework for personality or attitude [was] explicitly named" (yes or no) was documented. Furthermore, the methodological approaches to assessing personality ("personality model applied or facets assessed," "instrument used to assess personality") and attitude ("instrument used to assess attitude," "attitude-items considered individually or attitude-classes generated," "attitude classes assessed or extracted from the items," "statistical method for generating attitude-class," and

Table 2. Concepts and keywords operated in the final database search in German ${ }^{1}$

\begin{tabular}{|c|c|c|c|c|}
\hline Concept 1 & Concept 2 & Concept 3 & Concept 4 & Concept 5 \\
\hline \multirow{5}{*}{ Nutztierhalter } & Einstellung* & Tierwohl & *kühe & Einflüsse \\
\hline & & Produktivität & Milchvieh* & Korrelation* \\
\hline & & & Kalb & Beziehung* \\
\hline & & & Kälber* & Zusammenh* \\
\hline & & & Färse* & Assoz* \\
\hline
\end{tabular}

${ }^{1}$ Columns are linked with Boolean AND operators. Rows are linked with Boolean OR operators. * indicates a wildcard operator allowing any number of additional letters. 
"method used to analyze risk factors" were documented. "Number of items and scales provided" was extracted concerning the assessment of personality and attitude. As attitudes are connected to specific psychological objects (Ajzen, 2001), this was extracted as well ("psychological object"). At this point, the exact wording used to label the psychological objects was extracted from the records without adding any interpretation concerning their meaning. Subsequently, psychological objects were aggregated into generic terms and topics.

To determine whether risk factors (personality and attitude) are related to (which) dependent variables, "relationship between attitude and dependent variable" and "relationship between personality and dependent variable" (yes or no) were extracted.

We assessed possible factors that may hinder an overall conclusion on the effect of attitudes and personality. Focus was on data collection and processing (e.g., summing up information on attitude or personality in scores or latent data) and on conducting risk factor analyses. Additionally, the disclosure of questions/ items used for risk factor analyses was assessed ["Items used for personality assessment made accessible" (yes or no) and "Items used for attitude assessment made accessible" (yes or no)].

\section{RESULTS}

\section{Spectrum of Studies on Personality and Attitude as Risk Factors}

In total, 1,144 records were captured by the search strategy. Figure 1 illustrates the paper selection steps and the number of studies excluded at each step. The main reasons for excluding records were (1) presenting only descriptive results on personality and attitude, (2) considering attitude as an outcome, (3) considering outcomes, which were not meeting the eligibility criteria, (4) investigating effects of intervention aiming to change attitudes, and (5) dealing with beef cattle.

In all, 38 records meeting eligibility criteria were identified and included in the review. The completed data extraction sheet can be accessed as supplementary material (Supplemental File S1; https://doi.org/10 .3168/jds.2018-15037). Publication years ranged from 1972 (Seabrook, 1972) to 2017 (DeLong et al., 2017; Kayitsinga et al., 2017). Most publications assessed attitudes as risk factors $(\mathrm{n}=33 ; 86.8 \%), 4$ publications assessed attitude and personality $(\mathrm{n}=4 ; 10.5 \%)$, and 1 assessed personality only $(\mathrm{n}=1 ; 2.6 \%)$. Research on the effects of farmers' personalities and attitudes on dairy cattle health, welfare, productivity, and management as far as captured by this review includes data from 19 different countries. Half of this research was conducted in the United Kingdom, the Netherlands, and Norway ( $\mathrm{n}=19 ; 50 \%$; Table 3 ). The dependent variables were related to dairy cattle health $(\mathrm{n}=13$ publications), welfare $(\mathrm{n}=4)$, productivity $(\mathrm{n}=11)$, and farm management $(\mathrm{n}=17)$.

Theoretical Background. Four of 5 papers investigating personality presented at least basic information on the theoretical background underpinning their assessment. Three of 5 articles referred to the Big Five personality traits as a basis for their assessment. Seabrook (1972) and Waiblinger et al. (2002) indicated no specific theoretical background behind their personality assessment. Only Alvarez and Nuthall (2006) presented explicit theoretical backgrounds on the relationship between personality and outcome variables, referring to the Information Innovation Adoption Model (Agarwal and Prasad, 1998).

Theoretical background for assessing attitude grounded in socio-psychological research was provided in $48.7 \%(\mathrm{n}=18)$ of the papers. Theoretical backgrounds explicitly mentioned were the Theory of Planned Behavior $(\mathrm{n}=5)$, Theory of Reasoned Action $(\mathrm{n}=5)$, Health Belief Model $(\mathrm{n}=1)$, Behavioral Economics $(\mathrm{n}=1)$, and Social Ecology Model $(\mathrm{n}=1)$. Two papers referred to more than one theory. Papers not explicitly mentioning the theoretical background behind their research provided citations leading to corresponding social science information $(\mathrm{n}=6)$. Finally, $50 \%(\mathrm{n}=17)$ of papers provided no information on the socio-psychological background.

Data Collection. Four of 5 studies assessing farmers' personalities employed self-report questionnaires. Within the publications included $(\mathrm{n}=5), 11$ personality domains were assessed (Table 4). For that purpose, Hanna et al. (2009) obtained a questionnaire from the International Personality Item Pool (http://ipip.ori .org; 2001), whereas Arias and Spinka (2005) employed the Czech standard short version of the NEO Big Five Personality Inventory adapted from Costa and McCrae (1992). Alvarez and Nuthall (2006) employed a locally developed item set to assess the Big Five personality domains. Seabrook (1972) and Waiblinger et al. (2002) did not use a conventional personality test but rather a self-developed item set. All questionnaires, except the one used by Seabrook (1972), included a set of statements to be rated by the respondent. Each statement coded for one specific personality domain only; however, each domain could be assessed through several statements. The number of statements coding for a domain depended on the questionnaire. To rate the items, Arias and Spinka (2005) and Hanna et al. (2009) provided Likert scales to the respondents. Waiblinger et al. (2002) operated a semantic differential scale. Alvarez and Nuthall (2006) did not report the scale used to 
rate the questionnaire items. Seabrook (1972) initially provided respondents with questions during structured interviews; however, this approach proved to be inappropriate when piloting it. Consequently, an approach based on the "play technique" was used.

Psychological objects were of interest in assessing attitudes. Given that exact wording was taken as presented in the papers without interpreting textual meanings, 35 psychological objects were assessed. Fourteen studies (37.8\%) reported to have investigated attitudes toward more than one psychological object. Most studies investigated attitudes toward animal diseases, their diagnostics, and therapy $(\mathrm{n}=20$; Table 5$)$.

Twenty-five papers $(67.6 \%)$ reported having used questionnaires completed by respondents. Questionnaires were completed in person during farm visits $(\mathrm{n}=$ 11 ) or sent to respondents by post $(\mathrm{n}=9)$ or email ( $\mathrm{n}$ $=1$ ). In 1 further study, respondents could answer the questionnaire online only, and 3 other papers reportedly let the respondent decide whether to answer on paper or online.

Eleven papers $(29.7 \%)$ used interviews to investigate attitudes. Nine $(81.8 \%)$ conducted interview questionnaires face to face $(\mathrm{n}=5)$ or via telephone $(\mathrm{n}=4)$. Two papers (18\%) reported using semi-structured face-to-face interview techniques. One paper reported conducting farm visits and studying stockpersons based on the "play technique" (Seabrook, 1972).

The number of items presented to the respondents ranged from a single item to 157 (Waiblinger et al., 2002). Seven papers (18.9\%) did not indicate the number of items included. Based on existing information, the average number of items was 24. For quantitative approaches, Likert scales were used most frequently (91\%; $\mathrm{n}=31$ papers). In 1 study (Alemayehu et al., 2010), researchers asked respondents to answer a ques-

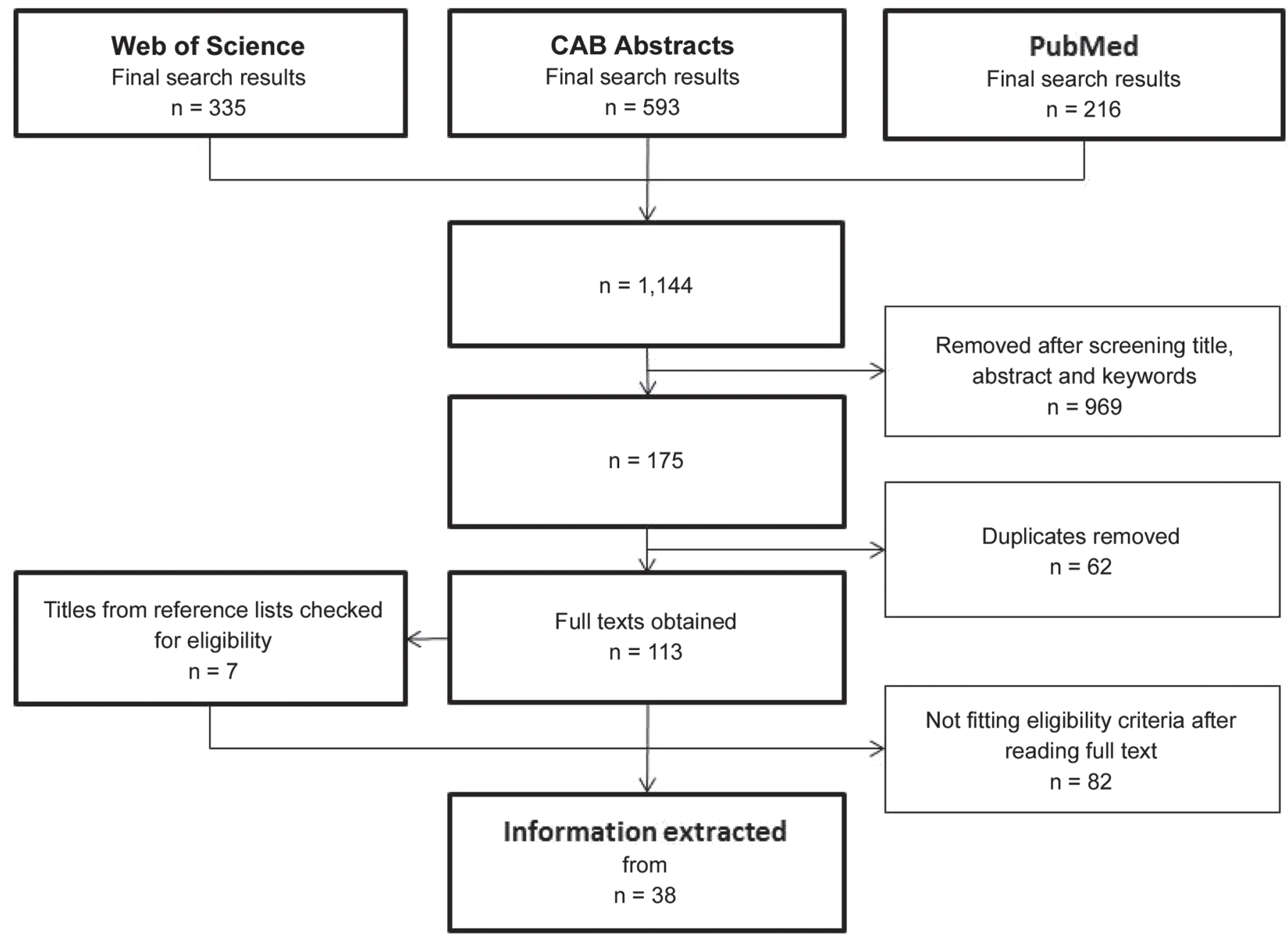

Figure 1. Number of records captured in final database searches and removed at different stages of the paper selection process. 
Table 3. Numbers (n) of records per country (38 records included)

\begin{tabular}{lc}
\hline Country of research & Records $(\mathrm{n})$ \\
\hline United Kingdom & 11 \\
Netherlands & 5 \\
Norway & 3 \\
Australia & 2 \\
Austria & 2 \\
United States & 3 \\
Sweden & 2 \\
Finland & 2 \\
Denmark & 2 \\
Czech Republic & 1 \\
France & 1 \\
Canada & 1 \\
India & 1 \\
Ethiopia & 1 \\
Japan & 1 \\
New Zealand & 1 \\
Uruguay & 1 \\
Belgium & 1 \\
Mexico & 1 \\
Total & $43^{1}$
\end{tabular}

${ }^{1}$ One study included data from Norway, Sweden, Finland, and Denmark. Another included data from New Zealand and Uruguay.

tion on a binary (yes/no) scale. Two papers (6\%) did not indicate which scale was used.

Interviewees' responses to open-ended questions included in qualitative interviews were audio recorded and transcribed word-for-word to extract subsequent information (Heffernan et al., 2008; Vaarst and Sorensen, 2009).

Item Disclosure. No papers provided the complete wording of the items used to assess personality data. Two papers referenced these items by citing other studies or technical literature (Arias and Spinka, 2005; Alvarez and Nuthall, 2006). Hanna et al. (2009) presented a web link to the questionnaire used; however, this link was inactive when we tried it. Waiblinger et al. (2002) provided one example from the 14 statements they used to assess personality.

Twenty papers $(54 \%)$ that investigated farmers' attitudes disclosed all items in text or tables $(\mathrm{n}=19)$ or in supplementary material $(\mathrm{n}=1)$. Seventeen $(46 \%)$ provided no comprehensive information on the items used. One paper (Schewe et al., 2015) included a web link for that purpose; however, it was inactive at the time this review was undertaken.

Information Extraction and Data Processing. Information on extracting personality dimensions and processing data to assess personality was presented in 2 of 5 publications (Waiblinger et al., 2002; Arias and Spinka, 2005). Arias and Spinka (2005) provided stockpersons with a questionnaire containing 60 selfdescription items to rate on a 5-degree scale, ranging from "fully agree" to "fully disagree." Twelve items represented each personality dimension. To measure each of the 4 dimensions, the average score was calculated from the 12 items coding that dimension. Waiblinger et al. (2002) used principal components analysis and varimax rotation to reduce the 14 self-descriptive items in their questionnaire. The result was 3 components representing personality dimensions, which were labeled as "agreeable," "confident-extravert," and "pessimistic."

Attitude information extraction and data processing methods differed between studies depending on the technique used to obtain the primary data. Two major approaches to extracting attitude information in quantitative research were found. Twenty-five papers $(73.7 \%)$ condensed items into smaller numbers of attitudes classes or into an overall attitude. Six (17.7\%) considered each questionnaire item in the risk factor analysis. Two papers (5.8\%) combined both approaches. One paper (Bertenshaw and Rowlinson, 2009) provided no comprehensible information on information extraction.

Principal components analysis was the most common procedure for condensing attitude items $(52 \%$; $\mathrm{n}=13)$, followed by summing single item scores to calculate a final attitude score $(16 \% ; \mathrm{n}=4)$. Other papers used procedures such as factor analysis (Vande Velde et al., 2015; Fukasawa et al., 2017), structural equation measurement models (Toma et al., 2013; Toma et al., 2015), or transforming a 5-point Likert scale into a dichotomous outcome (Kielland et al., 2010).

Content analysis (Heffernan at al., 2008) and a modified grounded theory approach (Vaarst and Sorensen, 2009) were used to code information from semi-structured interviews. Seabrook (1972) used records (e.g., percentage distribution of comments made by stockmen, stockman cow interactions) to extract attitude information by comparing the different stockmen.

Risk Factor Analysis. After extracting personality dimensions, risk factor analysis was conducted using Spearman correlation (Waiblinger et al., 2002;

Table 4. Personality domains assessed as named by the authors (4 records included)

\begin{tabular}{lc}
\hline Personality domain & $\begin{array}{c}\text { Records assessing } \\
\text { this domain (n) }\end{array}$ \\
\hline Extraversion & 3 \\
Agreeableness & 3 \\
Conscientiousness & 3 \\
Neuroticism & 2 \\
Emotional stability & 1 \\
Intellect & 1 \\
Agreeable & 1 \\
Confident extravert & 1 \\
Pessimistic & 1 \\
Openness to experience & 1 \\
Openness & 1 \\
\hline
\end{tabular}


Table 5. Psychological objects and topics considered for attitude assessment (37 records included $)^{1}$

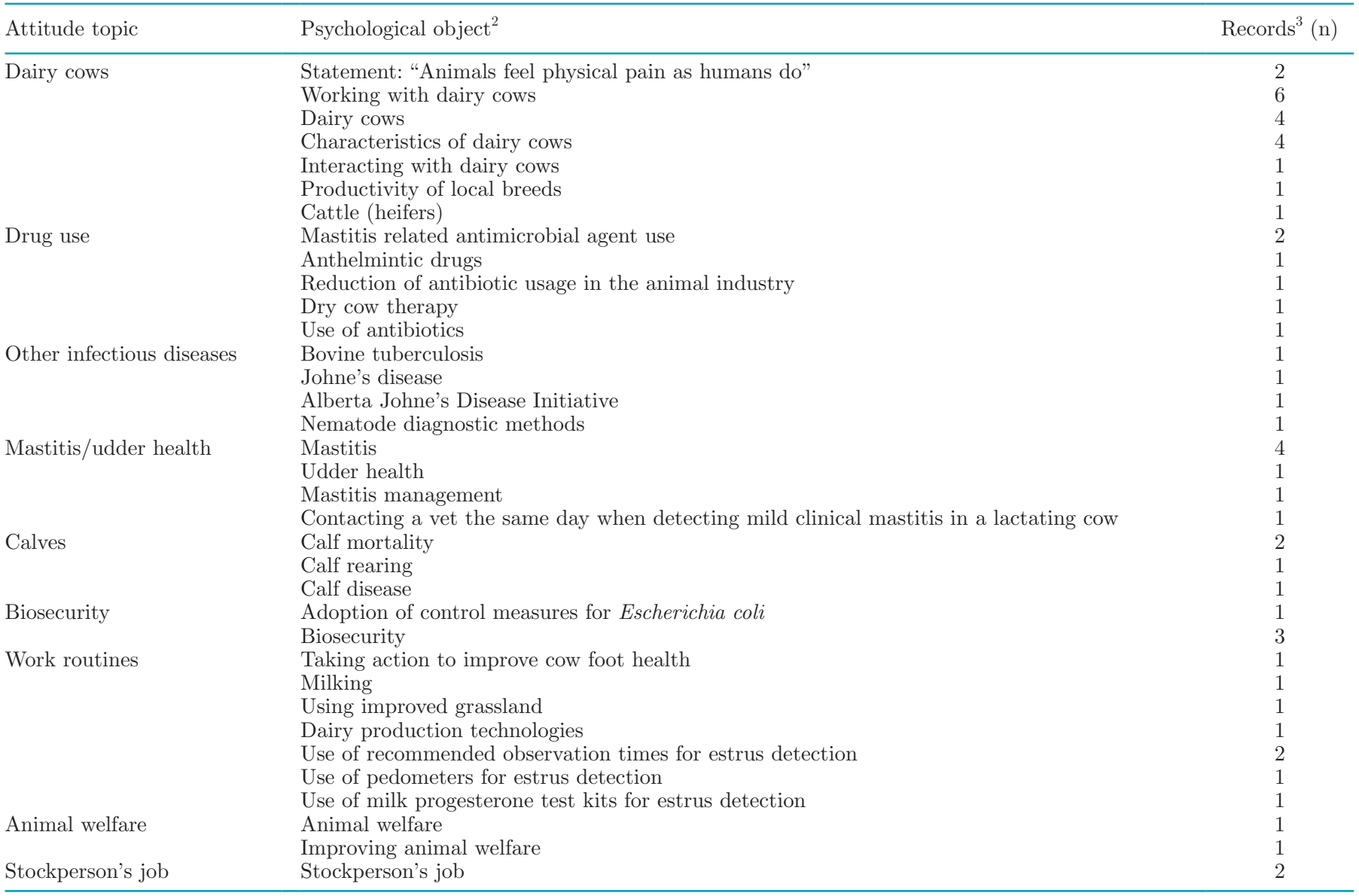

${ }^{1}$ Because some papers investigated attitudes toward more than one psychological object, these papers are displayed more than once.

${ }^{2}$ Wording was taken over as presented in the records without any interpretation concerning textual meanings.

${ }^{3}$ Number of records assessing attitude toward that psychological object.

Arias and Spinka, 2005) and partial correlation analysis (Hanna et al., 2009). Alvarez and Nuthall (2006) looked for direct relationships between personality dimensions and outcome variables by the $t$-test, MannWhitney U test, and chi-squared test. Only variables directly affecting the outcome variables were included in a structural equation model. Correlation coefficients or standardized regression weights were used to investigate relationships between personality dimensions and outcome variables.

Diverse statistical methods were used to analyze risk factors investigating attitudes. Correlational analysis (e.g., Spearman correlation, Pearson correlation, and partial correlation analysis) and regression analysis (e.g., linear regression, logistic regression, and regression tree analysis) were the most frequently mentioned approaches, followed by structural equation modeling.

Vaarst and Sorensen (2009) conducted semi-structured qualitative interviews to assess attitudes, using modified grounded theory to extract attitude themes.
They compared 2 groups of farms (high vs. low calf mortality) relative to the attitude themes farmers mentioned during their interviews. Related conformities and differences were analyzed to evaluate the effect of attitude on calf mortality.

\section{Relationship Between Personality and Dairy Cattle Health, Welfare, Productivity, and Management}

Three of the 5 studies assessing farmers' personalities reported it to be at least partially related to the dependent variables. When Waiblinger et al. (2002) assessed 3 personality components ("agreeable," "confidentextravert," and "pessimistic"), only "agreeableness" was significantly negatively correlated with the percentage of farmers' neutral and negative behaviors toward cows. In contrast, "agreeableness" was positively correlated with farmers' positive behaviors toward cows during milking. Arias and Spinka (2005) reported that "neuroticism" in stockpersons was negatively correlated 
with average herd milk yield in kilograms per standardized lactation, and also positively correlated with mean veterinary care costs per dairy cow and year on the farm. Neuroticism, here, is defined as emotional lability (Roccas et al., 2002). This dimension can be divided into 6 facets (anxiety, anger, depression, selfconscientiousness, immoderation, and vulnerability).

Conversely, "conscientiousness" was negatively correlated with veterinary costs. This dimension comprises the facets self-efficacy, orderliness, dutifulness, achievement striving, self-discipline, and cautiousness, thus representing a person's tendency to be careful or vigilant (Roccas et al., 2002). Seabrook (1972) found the personality of stockmen to affect milk yield and suggested that this was because some farmers achieved a better HAR on their farms.

Although they assessed the same Big Five personality traits as Arias and Spinka (2005), Hanna et al. (2009) identified no relevant direct correlation between personality domains and milk yield. Furthermore, Alvarez and Nuthall (2006) revealed no relevant direct relation between personality domains and farmers adopting computer-based information systems.

\section{Relationship Between Attitudes and Dairy Cattle Health, Welfare, Productivity, and Management}

Table 6 (alternative format: Supplemental Table S1; https://doi.org/10.3168/jds.2018-15037) provides an overview of reported relationships between dependent variables sorted by thematic areas and attitudes. Extracting the exact wording for psychological objects from the records led to diverse combinations of attitudes and dependent variables. Therefore, it was impossible to determine reported relationships between all dependent variables and attitudes. More than 50 dependent variables were investigated overall. Four of 37 papers $(10.8 \%)$ found no relevant relationships between attitude and dependent variables. In the following, despite differing methodological approaches, we highlight findings on the effect of attitudes from the reviewed studies within the different thematic outcome areas. These will be discussed later on concerning their possible consideration for future research or professionals in the field.

Effect of Attitudes on Animal Health. The effect of attitudes on milk SCC was investigated within various studies. Schewe at al. (2015) and Jansen et al. (2009) showed that SCC were associated with farmers' attitudes toward mastitis. Higher cell counts were shown to be positively associated with the farmer seeing mastitis and not following milking and treatment protocols as a problem on his farm (Schewe et al., 2015). Furthermore, the farmers' perception of control over the problem was revealed to be negatively correlated with cell counts (Jansen et al., 2009; DeLong et al., 2017) and the incidence of clinical and subclinical mastitis (DeLong et al., 2017). In addition, Tarabla and Dodd (1990) showed that farms on which the stockperson evaluated the task of milking as positive (i.e., positive attitude toward milking) were less likely to show high cell counts.

A positive attitude toward calf mortality and calf disease (i.e., the farmer feeling in control of the situation) was shown to negatively affect farms' calf mortality rates (Vaarst and Sorensen, 2009). Santman-Berends et al. (2014) revealed that farmers who reported to see a dead calf as a problem to have lower mortality rates and those considering a stillbirth from a cow more severe than a stillbirth from a heifer to have higher rates. Silverlas and Blanco-Penedo (2013) found an association between positive attitudes toward biosecurity (i.e., considering biosecurity as important) and lower cryptosporidial prevalence in calves on farms. Kielland et al. (2010) investigated the effects of farmers' attitudes toward pain in cattle on the prevalence of lesions on the hock and carpus of cows. Farmers indicating agreement to the statement "animals feel pain as humans do" were more likely to have low prevalence of hock and carpus lesions on their farms. Furthermore, the prevalence of lame cows was shown to correlate with attitudes toward cows (Rouha-Mulleder et al., 2009). Prevalence increased with farmers indicating a higher intention to use negative behavior when moving cows and decreased with farmers reporting dislike of such negative behavior. Broughan et al. (2016) showed the odds of a bovine tuberculosis (bTB) case to be associated with farmers' attitudes toward bTB. Farmers seeing their animals as less under threat of other cattle as possible carriers of the disease and farmers less likely to think that other people or institutions could help them to solve the problem of bTB had higher odds to be a case farm.

Effect of Attitudes on Welfare. The effect of stockpersons' attitudes on dairy cattle welfare was investigated by studying the behavior of cows in presence of humans. Assessing the effect of stockpersons' attitudes toward "characteristics of cows" and "working with dairy cows," Breuer et al. (2000) reported that positive attitudes toward cows were negatively correlated with aversive cow behavior (i.e., flinch, step, and kick responses) in the milking parlor. des Roches et al. (2016) revealed that farmers with a more negative behavioral attitude toward cows had a lower proportion of cows accepting to be touched in a standardized avoidance distance test.

Effect of Attitudes on Productivity. Milk yield and milk contents were investigated concerning their re- 
lation to farmers' attitudes in various studies. Attitudes toward cows (i.e., cows' characteristics and working with dairy cows) were the psychological objects used most frequently within this research area. Employing the same questionnaire items and answer scales to assess attitudes, Hanna et al. (2009) extracted 4 factors ("empathy," "negative beliefs," "job satisfaction," and "patience") from the raw data, whereas Fukasawa et al. (2017) extracted only 3 ("positive beliefs," "negative beliefs," and "job satisfaction"). Risk factor analysis findings also differed. Fukasawa et al. (2017) found only "positive beliefs" to be positively related to milk yield. In contrast, whereas Hanna et al. (2009) found the attitude classes "empathy" and "job satisfaction" to be

Table 6. Relationships between attitudes (toward different psychological objects) and dependent variables (sorted by thematic areas) $)^{1,2}$

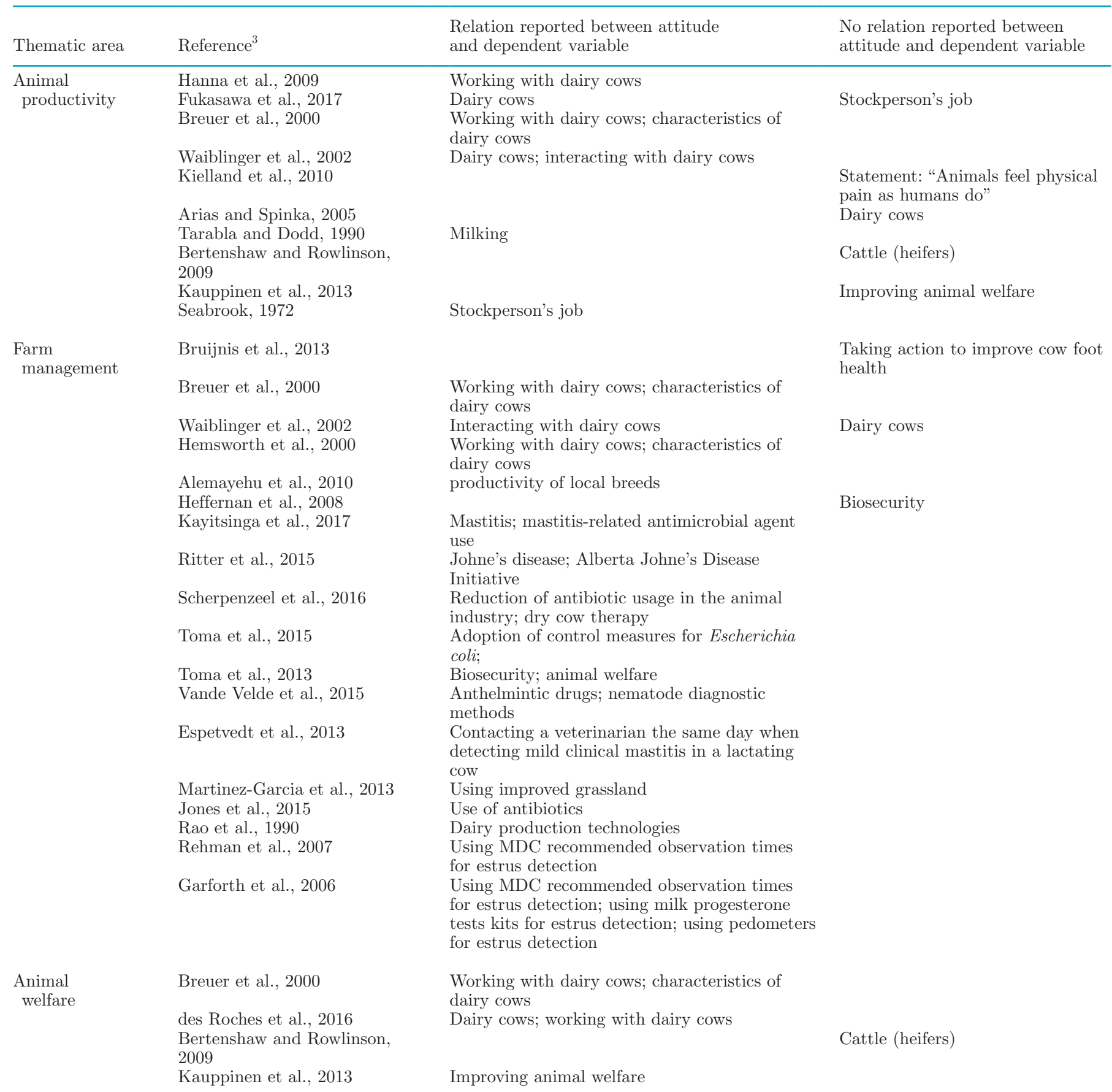


Table 6 (Continued). Relationships between attitudes (toward different psychological objects) and dependent variables (sorted by thematic areas $)^{1,2}$

\begin{tabular}{|c|c|c|c|}
\hline Thematic area & Reference $^{3}$ & $\begin{array}{l}\text { Relation reported between attitude } \\
\text { and dependent variable }\end{array}$ & $\begin{array}{l}\text { No relation reported between } \\
\text { attitude and dependent variable }\end{array}$ \\
\hline $\begin{array}{l}\text { Animal } \\
\text { health }\end{array}$ & $\begin{array}{l}\text { van den Borne et al., } 2014 \\
\text { Vaarst and Sorensen, } 2009 \\
\text { Schewe et al., } 2015 \\
\text { Jansen et al., } 2009 \\
\text { Kielland et al., } 2009 \\
\text { Arias and Spinka, } 2005 \\
\text { Broughan et al., 2016 } \\
\text { Rouha-Mulleder et al., } 2009 \\
\text { Tarabla and Dodd, } 1990 \\
\text { Santman-Berends et al., } 2014 \\
\text { Silverlas and Blanco-Penedo, } \\
2013 \\
\text { Kielland et al., } 2010 \\
\text { DeLong et al., } 2017\end{array}$ & $\begin{array}{l}\text { Udder health } \\
\text { Mastitis; mastitis-related antimicrobial agent } \\
\text { use } \\
\text { Mastitis } \\
\text { Statement: "Animals feel physical pain as } \\
\text { humans do" } \\
\text { Bovine tuberculosis } \\
\text { Working with dairy cows; characteristics of } \\
\text { dairy cows } \\
\text { Milking } \\
\text { Calf mortality; calf rearing } \\
\text { Biosecurity } \\
\text { Statement: "Animals feel physical pain as } \\
\text { humans do" } \\
\text { Mastitis }\end{array}$ & Calf mortality; calf disease \\
\hline
\end{tabular}

${ }^{1}$ Complete list of dependent variables: dairy cows; working with dairy cows; mastitis; biosecurity; characteristics of dairy cows; mastitis-related antimicrobial agent use; calf mortality; statement: "Animals feel physical pain as humans do"; interacting with dairy cows; reduction of antibiotic usage in the animal industry; taking action to improve cow foot health; udder health; stockperson's job; bovine tuberculosis; productivity of local breeds; Johne's disease; Alberta Johne's Disease Initiative; calf rearing; dry cow therapy; adoption of control measures for Escherichia coli; animal welfare; anthelmintic drugs; nematode diagnostic methods; milking; contacting a veterinarian the same day when detecting mild clinical mastitis in a lactating cow; using improved grassland; improving animal welfare; dairy production technologies; calf disease; use of antibiotics; cattle (heifers); using Milk Development Council (MDC) recommended observation times for estrus detection; mastitis management; using milk progesterone tests kits for estrus detection; using pedometers for estrus detection.

${ }^{2}$ An alternative version of this table is given in Supplemental Table S1 (https://doi.org/10.3168/jds.2018-15037) that shows the same information in an "at-a-glance" format.

${ }^{3}$ Some papers investigated dependent variables from more than one thematic area, so these papers are listed more than once.

positively correlated with milk yield, no such correlation was found for milk yield and "patience." "Negative beliefs," however, negatively affected milk yield. The association between job satisfaction and milk yield is in compliance with Seabrook (1972) who found attitudinal factors related to job satisfaction (i.e., perceived level of stress, motives, emotion) to be associated with milk yield. Breuer et al. (2000) found a positive composite attitude toward cows (including items related to petting and talking to cows, ease of movement of cows, and the ability of cows to recognize unfamiliar stockpersons) to be positively correlated with milk yield and protein contents, whereas Kauppinen et al. (2013) did not find any associations between farmers attitude toward improving animal welfare and milk yield. Nor did Arias and Spinka (2005) reveal any associations between farmers' attitudes toward dairy cows and productivity.

Attitude and Farm Management. Bruijnis et al. (2013) found farmers' positive attitude toward the belief that foot health could really be improved by taking action to be positively correlated with their reported intention to improve cow foot health. Toma et al. (2015) aimed to identify attitudes modulating farmers' behavioral willingness to control Escherichia coli infections on their farms. Knowledge about the pathogen, the feeling of responsibility, and former experience with related infections on the farm were identified to be drivers that positively affected farmers' willingness to take action. Conversely, Heffernan et al. (2008) did not reveal any comprehensible relationship between attitudes toward individual versus collective biosecurity behavior and attitudes toward biosecurity regulation and participation in biosecurity collective action among farmers. Also related to the biosecurity aspect, Ritter et al. (2015) investigated whether farmers participated in a voluntary management-based Johne's disease control program. Attitudes toward the disease and the control program were considered potential influencing factors. The results showed participants to have higher self-assessed knowledge of Johne's disease and better understanding of the control programs' details. Nonparticipants' attitudes indicated time to be a major on-farm constraint, and those farmers stated that participation in the program would take them too much time.

Other research was concerned with management decisions related to therapy of diseases and drug use. The effect of farmers' attitudes toward mastitis and employee training on the frequency of mastitis-related antibiotic drug use ("intramammary" and "systemic") 
was investigated by Kayitsinga et al. (2017). Their results showed that farmers who believed that "bad luck" plays an important role in mastitis problems were more likely to apply "intramammary" and farmers who financially penalized their employees in case of increased cell counts were more likely to apply "systemic." Scherpenzeel et al. (2016) found that attitudes toward dry cow therapy and reduction of antibiotic usage in the animal industry were related to whether farmers were performing selective dry cow treatment instead of blanket dry cow treatment on their farms. Three attitudinal variables were found to affect this decision: The beliefs that financial consequences were one of the most important negative aspects of reducing antibiotic usage and uncertainty whether a cow would recover from mastitis without antimicrobials were both related to a higher odds that farmers were applying blanket dry cow treatment on their farms. Similarly, Jones et al. (2015) investigated farmers' intention to reduce onfarm antibiotic usage over the next 12 mo. Although the calculated overall attitude did not show to be related, single aspects such as thinking that reducing antibiotic usage would be a good thing, would lower the costs, and would increase consumer confidence in milk and milk products correlated positively with intention to reduce antibiotic usage. Vande Velde et al. (2015) found farmers' attitudes toward "anthelmintic drugs" and "nematode diagnostic methods" to be associated with farmers' intention to adopt diagnostic methods before implementing anthelmintic drugs. Negative attitudes toward diagnostics (constructed of the items good-bad, useful-useless, and beneficial-harmful) were shown to be negatively associated with uptake of diagnostics, whereas positive attitudes toward the use of anthelmintic drugs positively affected the intention to perform previous diagnostics.

Investigating the effect of attitudes on the HAR, Hemsworth et al. (2000) and Breuer et al. (2000) investigated the effect of farmers' attitudes toward dairy cows on human behavior during milking. Breuer et al. (2000) found that positive attitudes were negatively correlated with the percentage of highly negative tactile interaction during milking and positively correlated with the proportion of quiet and soft vocalizations of farmers. Hemsworth et al. (2000) also revealed that stockpersons' positive attitudes toward the behavior of dairy cows correlated negatively with the number of forceful tactile interactions during cow handling.

Concerning investigation of the uptake of general management aspects on dairy farms, Alemayehu et al. (2010) reported that Ethiopian farmers' preferable attitudes toward the production of indigenous Horo cattle was a determinant for the decision to choose that market-oriented business. Questioning which factors might influence the adoption of improved grassland management among small-scale dairy farmers in Mexico, Martinez-Garcia et al. (2013) reported that positive attitudes toward that option (i.e., decrease of costs, increase of milk yield, easy to manage) promoted the uptake, whereas negative attitudes (e.g., requires availability of land, investments are not recovered from milk sales) prevented farmers from using improved grassland. Using the same questionnaire items for attitude assessment and theoretical framework (i.e., theory of reasoned action), Garforth et al. (2006) and Rehman et al. (2007), both showed that farmers' positive attitudes toward different approaches to better estrus detection (e.g., cost effectiveness, better detection rates) led to a higher intention to adopt recommended observation times, milk-progesterone test kits, and use of pedometers on their farms.

\section{DISCUSSION}

Here, we have systematically reviewed research considering farmers' personality and attitudes as risk factors for dairy cattle health, welfare, productivity, and farm management. The focus was on methodological approaches and whether overall contextual conclusions can be drawn on personalities' and attitudes' effect on outcome variables. We found methodological approaches to be diverse, thus hindering in-depth overall conclusions. Nevertheless, the comparison of paper findings indicated that farmers' personalities and attitudes affect dairy cattle health, welfare, productivity, and management. In general, attitudes indicating higher degrees of knowledge, awareness of problems, perceived responsibility, perception of control of a situation, a more positive HAR, and positive evaluation of the benefits of management decisions tended to affect outcomes in a beneficial way. While attitudes were related to all thematic (outcome) areas and personality measures were only reported to affect management aspects and dairy productivity, over-interpretation regarding a possible predominance of their effect on specific dairy production areas must not be done.

\section{Review Approach}

To date, as a consequence of expanding evidencebased practice across all sectors, the variety of review approaches is increasing (Grant and Booth, 2009). Scoping reviews, on the one hand, aim to identify the nature and extent of research evidence by preliminarily assessing the potential size and scope of research literature. They characterize quantity and quality of literature by study design and other key features. On the other hand, systematic reviews focus on appraisal and synthesis of 
research evidence. These often adhere to guidelines on the conduct of a review and address uncertainty around findings and what remains unknown, and develop recommendations for future research (Grant and Booth, 2009). Due to our objectives, we chose a mixed-method approach combining core aspects of systematic and scoping reviews as a tool for our investigations as we considered a mere quantification and quality assessment of literature as too superficial for the topic investigated. Per Grant and Booth (2009), meta-analysis is listed as an own category in the context of reviews. It is supposed to statistically combine the results of studies aiming to a more precise effect of results. Meta-analytic results are based on numerical analysis of effects assuming absence of heterogeneity between reviewed papers. However, our results showed the reviewed papers not to be appropriate for such synthesis at the current stage.

\section{Search Strategy}

The few references gathered from the reference lists of relevant publications indicated an efficient search strategy. By restricting publications to German and English, we may have missed publications. Gray literature and website searches were omitted. This would have been crucial for conduct of a meta-analysis, in which an overall effect is calculated based on the individual outcome of the identified articles (McAuley et al., 2000). However, due to the diversity of approaches, variables, and outcomes in the reviewed papers, a meta-analysis was not feasible. Instead, our review only included peer-reviewed publications that were deemed appropriate by experts in the same field (Kelly et al., 2014) to describe the effect of attitude and personality as risk factors for dairy cattle health, welfare, productivity, and farm management. Many publications were dismissed during paper selection as they considered attitude and personality as outcomes, reported only descriptive results, dealt with outcomes or species not meeting eligibility criteria, or focused on the effectiveness of intervention on attitudes. These articles may have an important effect regarding their research field; however, they did not yield information we needed (i.e., results and discussion about the effect of attitude and personality as risk factors for dairy cattle health welfare, productivity, and farm management).

We used well-known and evaluated methods and techniques to identify relevant literature and exclude irrelevant papers (e.g., Papaioannou et al., 2010). Nevertheless, the search strategy includes certain researcherspecific decisions, for example, on which concepts and key words to include or not to include. To substantiate our decisions we discussed them with colleagues from the dairy herd health unit and librarians of our uni- versity. Nevertheless, it cannot be ignored that other researchers would have decided on slightly different key words. Hence, this might have resulted in a slightly different list of papers. Therefore, we reported on the search strategy and our findings can only be related to this.

\section{Spectrum of Studies on Personality and Attitude as Risk Factors}

Research on personality and attitude as risk factors for dairy health, welfare, productivity, and management has involved researchers in many countries worldwide. We found that personality and attitude were investigated relative to their influence on management and dairy cattle health more frequently than on welfare and productivity (see Table 6 for attitude assessment). This might be because farmers' management decisions can be considered the basis for any activity implemented on farms and animal health is a basic requirement for achieving animal welfare and productivity. Another reason could be that management decisions and animal health parameters are easier to measure than welfare indicators and productivity, which require complex onfarm observations or analyzing secondary data such as production records.

Theoretical Background and Item Disclosure. Transparency is an important feature of scientific research. Miguel et al. (2014) stressed the importance of open data and materials, especially in social science research. Open data and materials "provide the means for independent researchers to: reproduce reported results; test alternative specifications on the data; identify misreported or fraudulent results; reuse or adapt materials (e.g., survey instruments) for replication or extension of prior research and; better understand the interventions, measures and context-all of which are important for external validity" (Miguel et al., 2014). We concentrated on whether 2 main aspects that we deemed important in the context of our review were presented lucidly. These were (1) explanation of theoretical backgrounds (including psychological objects) for risk factor assessment and (2) disclosure of questionnaire items or interview questions used.

Because theoretical backgrounds and items used to assess risk factors were not comprehensively reported in all records, future reporting might benefit from inclusion of more detailed information to enhance reproducibility and evaluation by independent researchers. Reporting the theoretical background, for example, increases the comprehensibility of study hypotheses. Theory of Planned Behavior or Theory of Reasoned Action, which have been mentioned as theoretical backgrounds for assessing attitude, link factors that affect 
a person developing certain behavioral intentions. The person's attitude is one of these factors, which may therefore help to predict behavior (Ajzen, 2001). These theories are especially applicable when the dependent variable is a behavioral intention or an observed behavior (Figure 2a). We investigated farm management as a thematic (outcome) area, and these theories can be directly applied to the effect of attitudes on farmers' behaviors or management decisions. However, most studies summarized in this review focused on outcome variables other than behavior or behavioral intentions (e.g., milk yield, prevalence of disease). Therefore, the analyzed risk factor and the outcome appeared to be indirectly related (Figure 2b). For example, when assessing the relationship between an attitude such as "empathy with the dairy cows" and milk yield (Hanna et al., 2009; Fukasawa et al., 2017), the hypothesis might be that a certain attitude influences the farmer toward a certain management decision, which itself increases or decreases the herd's milk yield. However, here the psychological object differs from the farmer's behavior, and the farmer's behavior itself is not assessed. Hence, this approach differs from the classical assessment of how attitude affects behavior, and this example illustrates why researchers should report the causal theory behind their hypotheses. When interpreting relationships between attitude and animal-related outcomes, it should be considered to which psychological objects an attitude was assessed and which farmer's behavior is suggested to affect animal-related outcomes. As one result of this review was that the associations between attitudes, psychological objects, and outcome were not always described in an easily comprehensible manner, visualization of the hypothesized associations may help to improve understanding (i.e., by use of causal diagrams; Dohoo et al., 2009). Here, all factors involved in the causal situation can be included, even those not analyzed.

Disclosing the items used to collect data is also important for ensuring clarity, particularly as no fixed item sets exist for assessing attitude, in contrast to personality. According to Schwarz and Bohner (2001), a question's answer or a statement's rating can be influenced by small changes in an item's wording or an answer scale's design. As attitudes toward identical psychological objects can be assessed using different

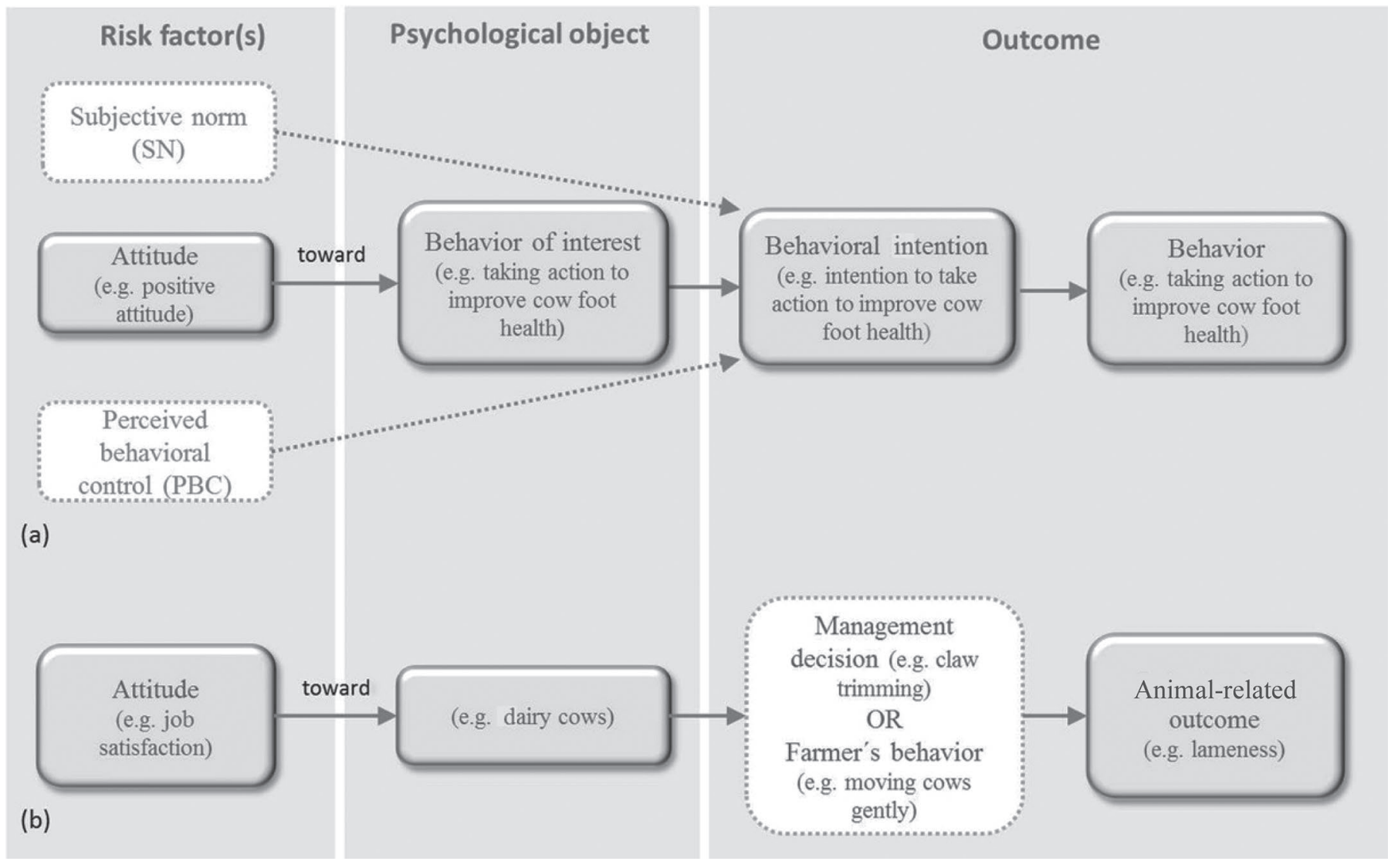

Figure 2. Causal diagram to assess the effect of attitudes on an outcome: (a) causal relation between farmers' attitude and farmers' behavior, and (b) causal relation between farmers' attitude and animal-related outcome. 
items, we encourage reporting questionnaire items to facilitate comparing and interpreting results.

Data Collection. In the studies included here, personality was assessed most often by those personality domains included in the Big Five model. However, the nomenclature in these domains was inconsistent between the articles (Table 4). This might be because the nomenclature differs even in the socio-psychologic literature. Therefore, it may be beneficial to develop harmonized nomenclature, at least within specific research fields (i.e., dairy science). Of course, the issue of nomenclature is not only apparent in this field of research. For example, different nomenclature and scoring systems exist for the assessment of lameness conditions in cattle (Penev, 2011).

Well-established and broadly accepted personality assessment theories exist, such as the Big Five or HEXACO. Item sets to assess personality domains are freely available and have been scientifically validated in different languages (Goldberg et al., 2006). These item sets contain different numbers of statements including validated short versions, which allow their use even when time or space is limited (Gosling et al., 2003; Ashton and Lee, 2009; de Vries, 2013); therefore, we believe that using unconventional, nonvalidated inventories should be avoided where possible, and if they are used this should be well-founded and explained.

In contrast to personality measures that are limited to a set number of theoretical domains and facets, no such limitation exists for attitudes. The variety of attitudes that can be investigated is as large as the number of psychological objects imaginable. The researcher must consider which and how many psychological objects (objects toward which attitude is assessed) are of interest regarding their possible influence on the dependent variables (farm-specific outcomes concerning animal health, welfare, productivity, and management). Again, this highlights why it so important to explain the theoretical background (e.g., by drawing a causal diagram; see discussion above). Furthermore, as can be seen from Table 5, where we proposed generic terms and topics to subsume psychological objects, harmonization of terms and definitions regarding certain wellinvestigated psychological objects would, in general, be possible and could increase future overall discussion of study findings.

Information Extraction and Data Processing. We focused on questioning the methods that the researchers chose. We did not evaluate whether the reported approaches were suitable for the data to which they were applied.

The common method for extracting personality data condenses several questionnaire items into a smaller number of personality dimensions. Using a validated inventory or item pool related to the Big Five or HEXACO clearly defines which items code for which personality dimension. However, this is not the case when self-tailored question sets are used to assess personality. In these cases, clear descriptions of the data extraction method are needed to ensure comprehensibility and reproducibility (Miguel et al., 2014).

When assessing attitudes, the researcher must decide how to condense items. Principal components analysis was used most frequently for that purpose in the studies in this review. The nomenclature of the resulting attitude classes remains the researcher's decision. Using the same questionnaire items and operating partial correlation analysis for extraction, Hanna et al. (2009) extracted 4 attitude classes related to the psychological object "working with dairy cows" out of 42 questionnaire items ("empathy," "negative beliefs," "job satisfaction," and "patience"), whereas Fukasawa et al. (2017) extracted only 3 attitude classes and labeled one differently ("positive beliefs," "negative beliefs," and "job satisfaction"). Hence, variation in procedures used to condense and deduce latent information may impair reproducibility. However, the fact that identical questionnaire items lead to different attitude classes supports our impression that attitude assessment results cannot be compared at the most detailed level, at least not under the given conditions without standardization of generic terms for psychological objects and a precise description of the anticipated association between attitude, psychological object, and outcome.

Risk Factor Analysis. Correlation and regression analyses were the methods used most frequently to analyze and interpret relations between farmers' personalities and outcomes. The process of classifying and interpreting the results differed in the parameters chosen to derive their significance and relevance. This heterogeneity is an obstacle to comparing the results and should be considered when interpreting them.

\section{Relationship Between Personality and Attitude and Dairy Cattle Health, Welfare, Productivity, and Management}

As $50 \%$ of the reviewed papers found personality influences, and $94 \%$ found attitude influences, we conclude that personality and attitude are likely to affect aspects of dairy cattle health, welfare, productivity, and farm management. However, we caution against over-interpretation of the finding that attitudes were related to all thematic (outcome) areas, whereas personality measures were only reported to affect management aspects and dairy productivity. One reason for this observation may be that the researchers' interests influenced their study hypotheses, and this should not 
be misinterpreted to imply that personality does not affect dairy health or welfare.

When considering whether an overall conclusion can be drawn regarding the effect of attitude and personality on dairy cattle health, welfare, productivity, and management, we believe that the complexity and heterogeneity must be considered, especially regarding attitude. Whereas a standardized and evaluated model and validated questionnaires exist for personality, there are diverse approaches to processing data, analyzing risk factors, and interpreting results. This can hinder comparison of studies even on identical attitudes.

Publication bias should be considered, as researchers who revealed no relationships between risk factors and outcome variables may be less likely to have published their results (Ioannidis, 2005), or scientific journals may have preferentially published detected effects and significant results (Dohoo et al., 2009). Furthermore, the thematic outcome variable areas we investigated here may have been of differing interest for scientists, professionals, or politicians in past years; therefore, they may have been excluded in scientific research to some degree. This may also have biased the information we could gather at this point. Finally, assuming that all observational studies considered in this review require voluntary participation, it is also necessary to consider selection bias. Therefore, results of the published papers may not be universally valid for the source population but restricted to the study group (Dohoo et al., 2009).

The heterogeneity of the psychological objects assessed and the variable methods applied to collect, analyze, and interpret data in attitude assessment impede development of a general overall conclusion of how attitudes affect dairy cattle health, welfare, productivity, and management. However, the answer to the question of which attitude affects which outcomes depends on the details of the view. As we show, farmer attitude toward "working with dairy cows" is associated with dairy cattle health, welfare, productivity, and management. However, each study extracted different information from different questionnaire items and extracted this information differently. Thus, diversity increases with the depth of detail. This issue, though, is not only apparent in attitude assessment. We discover this phenomenon also in other fields of veterinary science. For example, the recording of infection diagnostics may span from qualitative (yes/no in culture) over quantitative (optical density \% in ELISA) records toward molecular typing to describe the detection of pathogens. This could result in similar problems comparing findings due to different levels of detail. Hence, we have to expand our attention regarding this problem from the risk factors to the outcome variables, as well. When comparing information from different levels of detail, the most straightforward solution is to pull together information on the highest hierarchical level apparent (e.g., diagnostic test positive vs. negative). Although this may result in a loss of interpretative depth, it enables suggestion of an overall conclusion. Within the review presented here, this kind of higher level advance to compare study findings was applied especially on papers investigating farmers' attitudes as those showed the greatest amount of heterogeneity. As shown in Table 5 , it was possible to aggregate different psychological objects into topics. For that purpose it was necessary to consider the contextual meaning behind the detailed label of the psychological objects. In this case, the advance on a higher level of detail made it possible to come to overall conclusions. This points out the benefits of our detailed, framework-centered approach to this review. Focusing on details of theoretical frameworks is necessary to understand and use the concepts properly; however, putting results in relation to practical use (i.e., what do we learn by summing up different research results) requires a wider view of results. Nevertheless, it has to be taken into consideration that comparing results of different papers on a higher level of detail might also lead to false overall conclusions.

Considering these methodological challenges this scoping review enabled some general overall conclusions regarding personality and attitude as possible risk factors for dairy cattle health, welfare, productivity, and management.

Health. It is comprehensible that job satisfaction (i.e., evaluating the task of milking as positive) positively affects cell counts (Tarabla and Dodd, 1990), as milking is a task that is characterized by a high degree of routine and maybe even monotony. Therefore, high regard of the task may lead to more conscientious work and might positively affect hygiene and inspection of animals, which are important to prevent mastitis and recognize udder infection at an early stage. However, the possibility of reverse causation should also be taken into account here. Having low SCC may lead to higher levels of job satisfaction, as mastitis problems could cause frustration and dissatisfaction. Another attitudinal aspect that has been shown to affect the animals' health is the farmers' evaluation of the managerial onfarm situation. Being aware of shortcomings (Schewe et al., 2015) and knowing about important parts of farm management (Silverlas and Blanco-Penedo, 2013) are important to make proper management decisions. The findings of Schewe et al. (2015), who reported that farmers seeing both, mastitis and not following protocols properly, as a problem was associated with higher cell counts, has to be interpreted carefully with regard to the direction of the association. Normally, one would expect such awareness to be a good basis for a change 
within management to tackle the problem. However, farmers' perceptions could also result in self-fulfilling prophecies, or the awareness of the shortcomings may only be a result of high cell counts. Other factors reported to affect animal health have to do with the empathic setting of the farmer. Thinking that animals feel pain as humans do (Kielland et al., 2010) indicates a high degree of emotional attachment to the animals and might result in better care. However, it was also observed that when a stillbirth from a heifer was regarded as less severe than a stillbirth from a cow, the farm health status might be affected negatively (Santman-Berends et al., 2014). Here, it becomes clear that farmers also have to consider economic factors, which may be evaluated as superior to emotional attachment with animals by some stockpersons. Finally, the fact that farmers with higher odds of being a bTB case felt more often that other people or institutions could not help them with their problems, stresses the fact that proper information and support strategies are crucial and this topic should be addressed by professionals and politicians.

Welfare. Results show that the concept of the HAR is in the center of the investigation of the effect of attitudes on animal welfare. Aversive cow behavior (flinches, steps, kicks in the milking parlor; Breuer et al., 2000) and avoidance distance within approach tests (des Roches et al., 2016) were shown to be influenced by farmers' attitudes toward the animals. Favorable attitudes resulted in better welfare. These results are in compliance with other research investigating the human effect on stress in farmed animals (e.g., Hemsworth et al., 1989; Jones, 1993). It has to be noted that both Breuer et al. (2000) and des Roches et al. (2016) assess the effect of attitudes on welfare as part of a hypothesized causal chain finally aiming on assessments of effects on productivity. Therefore, these studies may be seen as good examples for proper construction of hypotheses and good reporting of theoretical backgrounds.

Productivity. It is easily comprehensible that emotionally labile farmers (i.e., neurotic persons; Arias and Spinka, 2005) may affect the productivity of cows. This finding substantiates Seabrook (1972) who found certain traits (e.g., motives, emotion) to lead to decreased milk yield. Anxious, angry, or depressed persons may act accordingly when handling their animals. Stressed cows may then show a decreased milk yield as the negative effect of stress on the productivity of farmed animals has also been shown for various other species (Hemsworth et al., 1981, 2000; Barnett et al., 1992; Cransberg et al., 2000). On the other hand, Hanna et al. (2009) could not find a personal characteristic such as impatience to lead to decreased milk yield. Therefore, it seems of critical importance not to over-interpret all improper behavior of stockpersons as compulsory risk factors for milk yield. Animals can get used to different kinds of persons and the level of stress might decrease as the animals have adapted to a certain kind of handling, for example (Grandin, 1997). Hence, it could be of special interest to think about which other consequences might occur within the daily farm business, if the farmer scores high for the above-mentioned personality facets. Anger and depression might curb mental and emotional resources, which again may lead to a decreased ability of stockpersons to keep an overview on the needs of the animals and necessary tasks. It has been shown that feeling in control of a situation positively affects performance (Jansen et al., 2009; Vaarst and Sorensen, 2009). On the other hand, a lack of feeling in control can curb one's ability to act upon the real situation (Ajzen, 1991). In this context, being depressed could also result in the feeling of losing control. This hypothesis corresponds with the findings that attitude can affect milk yield, as well (Hanna et al., 2009: "empathy"; Breuer et al., 2000 and Seabrook, 1972: "job satisfaction"). Being satisfied with ones' job (i.e., working with dairy cows and being a farmer) and holding positive beliefs about cows (Fukasawa et al., 2017) is a prerequisite for an open-minded relationship with the animals, appropriate handling of cows (Hemsworth et al., 2000), openness to technical further education (i.e., gain of knowledge), and awareness of shortcomings or upcoming difficulties. The consequence can be proper management decisions. This might lead to less stressed and healthier cows and a higher milk yield.

Management. It is understandable that attitudes representing higher degrees of technical knowledge (Ritter et al., 2015; Toma et al., 2015) were shown to favorably mediate management decisions. Therefore, communication of knowledge (e.g., about characteristics of pathogens or aims of interventions) should be seen as an important aspect by professionals when providing farmers with advice. This is in compliance with the findings of Bruijnis et al. (2013) and Vande Velde et al. (2015) who revealed that farmers have to be convinced about the usefulness of management decisions to increase the odds of implementation. In addition to these aspects, farmers' management, decisions were also shown to depend on economic considerations . Making management decisions, farmers evaluate cost effectiveness (Martinez-Garcia et al., 2013; Jones et al., 2015; Scherpenzeel et al., 2016), ease of management (Martinez-Garcia et al., 2013), and time constraints (Ritter et al., 2015). These findings highlight that farmers might see themselves in an area of conflict. This conflict is expressed in the wish to make the best decision for their farm and feeling responsible (Toma et 
al., 2015), on the one hand, and economic pressure and high workloads, on the other hand; this may be very pertinent as both economic pressure and workload are serious issues within the dairy sector (Lunner Kolstrup et al., 2013). This conflict should also be kept in mind when evaluating effects related to job satisfaction and the issue of stress in daily farm business.

\section{CONCLUSIONS}

We provide an overview of research on the impact of farmers' personalities and attitudes on dairy cattle health, welfare, productivity, and farm management. Research suggests that farmers' personalities and attitudes influence dairy cattle health, welfare, productivity, and farm management. We believe that comparing manuscripts at a detailed level is impeded due to variable methods of collecting, analyzing, and interpreting data, the heterogeneity of psychological objects assessed, and the many dependent variables per thematic area investigated. However, comparison of papers on a less detailed level revealed that personality dimensions and attitudes indicating favorable traits and opinions are associated with better dairy cattle health, welfare, productivity, and farm management. We encourage full disclosure of materials, as well as consideration of ways to harmonize assessing attitudes and personality measures, to promote comparison and enhance interpretation of results. Further research on these farmer-intrinsic aspects and their consideration by professionals and decision-makers within the dairy sector and politics is strongly recommended to better understand the needs of dairy farmers and therefore develop tailored advice and support strategies.

\section{ACKNOWLEDGMENTS}

This work was financially supported by the German Federal Ministry of Food and Agriculture (BMEL) through the Federal Office for Agriculture and Food (BLE, Bonn, Germany), grant number 2814HS006.

\section{REFERENCES}

Agarwal, R., and J. Prasad. 1998. The antecedents and consequents of user perception in information technology adoption. Decis. Support Syst. 22:15-29.

Ajzen, I. 1985. From intentions to actions: A theory of planned behavior. Pages 11-39 in Action Control: From Cognition to Behavior. J. Kuhl and J. Beckmann, ed. Springer, Berlin, Germany.

Ajzen, I., 1991. The theory of planned behavior. Organ. Behav. Hum. Dec. 50:179-211.

Ajzen, I. 2001. Nature and operation of attitudes. Annu. Rev. Psychol. 52:27-58.

Ajzen, I. and M. Fishbein. 2000. Attitudes and the Attitude-Behavior Relation: Reasoned and Automatic Processes. Eur. Rev. Soc. Psychol. 11:1-33.
Alemayehu, B., A. Bogale, C. Wollny, and G. Tesfahun. 2010. Determinants of choice of market-oriented indigenous Horo cattle production in Dano district of western Showa, Ethiopia. Trop. Anim. Health Prod. 42:1723-1729.

Alvarez, J., and P. Nuthall. 2006. Adoption of computer based information systems - The case of dairy farmers in Canterbury, NZ, and Florida, Uruguay. Comput. Electron. Agric. 50:48-60.

Arias, J. L. P., and M. Spinka. 2005. Associations of stockpersons' personalities and attitudes with performance of dairy cattle herds. Czech J. Anim. Sci. 50:226-234.

Ashton, M. C. 2013. Chapter 2: Personality traits and the inventories that measure them. Pages 27-55 in Individual Differences and Personality. 2nd ed. M. C. Ashton, ed. Academic Press, San Diego, CA.

Ashton, M. C., and K. Lee. 2009. The HEXACO-60: A short measure of the major dimensions of personality. J. Pers. Assess. 91:340-345.

Barnett, J. L., P. H. Hemsworth, and E. A. Newman. 1992. Fear of humans and its relationships with productivity in laying hens at commercial farms. Br. Poult. Sci. 33:699-710.

Bertenshaw, C., and P. Rowlinson. 2009. Exploring stock managers' perceptions of the human-animal relationship on dairy farms and an association with milk production. Anthrozoos 22:59-69.

Beynon, N. M. 1991. Pig-primate interface. Pig Veterinary Journal 26:67-77.

Booth-Kewley, S., and R. Vickers Jr.. 1994. Associations between major domains of personality and health behavior. J. Pers. 62:281298.

Breuer, K., P. H. Hemsworth, J. L. Barnett, L. R. Matthews, and G. J. Coleman. 2000. Behavioural response to humans and the productivity of commercial dairy cows. Appl. Anim. Behav. Sci. $66: 273-288$.

Broughan, J. M., D. Maye, P. Carmody, L. A. Brunton, A. Ashton, W. Wint, N. Alexander, R. Naylor, K. Ward, A. V. Goodchild, S. Hinchliffe, R. D. Eglin, P. Upton, R. Nicholson, and G. Enticott. 2016. Farm characteristics and farmer perceptions associated with bovine tuberculosis incidents in areas of emerging endemic spread. Prev. Vet. Med. 129:88-98.

Bruijnis, M., H. Hogeveen, C. Garforth, and E. Stassen. 2013. Dairy farmers' attitudes and intentions towards improving dairy cow foot health. Livest. Sci. 155:103-113.

Colquhoun, H. L., D. Levac, K. K. O'Brien, S. Straus, A. C. Tricco, L. Perrier, M. Kastner, and D. Moher. 2014. Scoping reviews: Time for clarity in definition, methods, and reporting. J. Clin. Epidemiol. 67:1291-1294.

Costa, P. T., Jr., and R. R. McCrae. 1992. NEO personality inventoryrevised (NEO PI-R) and NEO Five-Factor-Inventory (NEO-FFI) professional manual. Psychological Assessment Resources, Odessa, FL.

Costa, P. T., and R. R. McCrae. 1994. Set like plaster? Evidence for stability of adult personality. Pages 21-40 in Can Personality Change? T. F. H. J. L. Weinberger, ed. American Psychological Association Books, Washington, DC.

Cransberg, P. H., P. H. Hemsworth, and G. J. Coleman. 2000. Human factors affecting the bahvior and productivity of commercial broiler chickens. Br. Poult. Sci. 41:272-279.

Danziger, K. 1993. Psychological objects, practice and history. Annals of Theoretical Psychology 8:15-47.

de Rooij, S. J. G., C. C. de Lauwere, and J. D. van der Ploeg. 2010 Entrapped in group solidarity? Animal welfare, the ethical positions of farmers and the difficult search for alternatives. J. Environ. Policy Plann. 12:341-361.

des Roches, A. B. d., I. Veissier, X. Boivin, E. Gilot-Fromont, and L. Mounier. 2016. A prospective exploration of farm, farmer, and animal characteristics in human-animal relationships: An epidemiological survey. J. Dairy Sci. 99:5573-5585.

de Vries, R. E. 2013. The 24-item Brief HEXACO Inventory (BHI). J. Res. Pers. 47:871-880.

de Vries, R. E., J. M. Tybur, T. V. Pollet, and M. van Vugt. 2016. Evolution, situational affordances of personality. Evol. Hum. Behav. 37:407-421. 
DeLong, K. L., D. M. Lambert, S. Schexnayder, P. Krawczel, M. Fly, L. Garkovich, and S. Oliver. 2017. Farm business and operator variables associated with bulk tank somatic cell count from dairy herds in the southeastern United States. J. Dairy Sci. 100:92989310.

Department for Environment, Farming and Rural Affairs. 2007. FAWC report on stockmanship and farm animal welfare. Accessed Mar. 1, 2018. https://www.gov.uk/government/publications/fawc-report -on-stockmanship-and-farm-animal-welfare.

Dohoo, I., M. Wayne, and H. Strythn. 2009. Veterinary Epidemiologic Research. 2nd ed. VER Inc., Charlottetown, PEI, Canada.

Espetvedt, M., A. K. Lind, C. Wolff, S. Rintakoski, A. M. Virtala, and A. Lindberg. 2013. Nordic dairy farmers' threshold for contacting a veterinarian and consequences for disease recording: Mild clinical mastitis as an example. Prev. Vet. Med. 108:114-124.

Feist, G. J. 1998. A meta-analysis of personality in scientific and artistic creativity. Pers. Soc. Psychol. Rev. 2:290-309.

Fukasawa, M., M. Kawahata, Y. Higashiyama, and T. Komatsu. 2017. Relationship between the stockperson's attitudes and dairy productivity in Japan. Anim. Sci. J. 88:394-400.

Garforth, C., K. McKemey, T. Rehman, R. Tranter, R. Cooke, J. Park, P. Dorward, and C. Yates. 2006. Farmers' attitudes towards techniques for improving oestrus detection in dairy herds in South West England. Livest. Sci. 103:158-168.

Goldberg, L. R., J. A. Johnson, H. W. Eber, R. Hogan, M. C. Ashton, C. R. Cloninger, and H. G. Gough. 2006. The international personality item pool and the future of public-domain personality measures. J. Res. Pers. 40:84-96.

Gosling, S. D., P. J. Rentfrow, and W. B. Swann. 2003. A very brief measure of the Big-Five personality domains. J. Res. Pers. 37:504528.

Grandin, T. 1997. Assessment of stress during handling and transport. J. Anim. Sci. 75:249-257.

Grant, M. J., and A. Booth. 2009. A typology of reviews: An analysis of 14 review types and associated methodologies. Health Info. Libr. J. 26:91-108.

Hanna, D., I. A. Sneddon, and V. E. Beattie. 2009. The relationship between the stockperson's personality and attitudes and the productivity of dairy cows. Animal 3:737-743.

Heffernan, C., L. Nielsen, K. Thomson, and G. Gunn. 2008. An exploration of the drivers to bio-security collective action among a sample of UK cattle and sheep farmers. Prev. Vet. Med. 87:358-372.

Hemsworth, P. H. 2003. Human-animal interactions in livestock production. Appl. Anim. Behav. Sci. 81:185-198.

Hemsworth, P. H., G. J. Coleman, J. L. Barnett, S. Borg, and S. Dowling. 2002. The effect of cognitive behavioral intervention on the attitude and behavior of stockpersons and the behavior and productivity of commercial dairy cows. J. Anim. Sci. 80:68-78.

Hemsworth, P. H., J. L. Barnett, G. J. Coleman, and C. Hansen. 1989. A study of the relationships between the attitudinal and behavioral profiles of stockpersons and the level of fear of humans and reproductive performance of commercial pigs. Appl. Anim. Behav. Sci. 23:301-314.

Hemsworth, P. H., J. L. Barnett, and C. Hansen. 1981. The influence of handling by humans on the behavior, growth and corticosteroids in the juvenile female pig. Horm. Behav. 15:396-403.

Hemsworth, P. H., G. J. Coleman, J. L. Barnett, and S. Borg. 2000 Relationships between human-animal interactions and productivity of commercial dairy cows. J. Anim. Sci. 78:2821-2831.

Ioannidis, J. P. A. 2005. Why most published research findings are false. PLoS Med. 2:e124.

Jansen, J., B. H. van den Borne, R. J. Renes, G. van Schaik, T. J. Lam, and C. Leeuwis. 2009. Explaining mastitis incidence in Dutch dairy farming: The influence of farmers' attitudes and behaviour. Prev. Vet. Med. 92:210-223.

Jones, P. J., E. A. Marier, R. B. Tranter, G. Wu, E. Watson, and C. J. Teale. 2015. Factors affecting dairy farmers' attitudes towards antimicrobial medicine usage in cattle in England and Wales. Prev. Vet. Med. 121:30-40.

Jones, R. B. 1993. Reduction of the domestic chick's fear of humans by regular handling and related treatments. Anim. Behav. 46:991-998.
Kauppinen, T., A. Valros, and K. M. Vesala. 2013. Attitudes of dairy farmers toward cow welfare in relation to housing, management and productivity. Anthrozoos 26:405-420.

Kayitsinga, J., R. L. Schewe, G. A. Contreras, and R. J. Erskine. 2017. Antimicrobial treatment of clinical mastitis in the eastern United States: The influence of dairy farmers' mastitis management and treatment behavior and attitudes. J. Dairy Sci. 100:1388-1407.

Kelly, J., T. Sadeghieh, and K. Adeli. 2014. Peer review in scientific publications: Benefits, critiques, \& a survival guide. EJIFCC $25: 227-243$.

Kielland, C., L. E. Ruud, A. J. Zanella, and O. Osteras. 2009. Prevalence and risk factors for skin lesions on legs of dairy cattle housed in freestalls in Norway. J. Dairy Sci. 92:5487-5496.

Kielland, C., E. Skjerve, O. Osteras, and A. J. Zanella. 2010. Dairy farmer attitudes and empathy toward animals are associated with animal welfare indicators. J. Dairy Sci. 93:2998-3006.

Liberati, A., D. G. Altman, J. Tetzlaff, C. Mulrow, P. C. Gøtzsche, J. P. A. Ioannidis, M. Clarke, P. J. Devereaux, J. Kleijnen, and D. Moher. 2009. The PRISMA Statement for Reporting Systematic Reviews and Meta-Analyses of Studies That Evaluate Health Care Interventions: Explanation and Elaboration. Public Library of Science, San Francisco, CA.

Lunner Kolstrup, C., M. Kallioniemi, P. Lundqvist, H.-R. Kymäläinen, L. Stallones, and S. Brumby. 2013. International perspectives on psychosocial working conditions, mental health, and stress of dairy farm operators. J. Agromedicine 18:244-255.

Martinez-Garcia, C. G., P. Dorward, and T. Rehman. 2013. Factors influencing adoption of improved grassland management by smallscale dairy farmers in central Mexico and the implications for future research on smallholder adoption in developing countries. Livest. Sci. 152:228-238.

McAuley, L., B. Pham, P. Tugwell, and D. Moher. 2000. Does the inclusion of grey literature influence estimates of intervention effectiveness reported in meta-analyses? Lancet 356:1228-1231.

McLeod, S. A. 2009. Attitude measurement. Accessed Mar. 15, 2018. www.simplypsychology.org/attitude-measurement.html.

Miguel, E., C. Camerer, K. Casey, J. Cohen, K. M. Esterling, A. Gerber, R. Glennerster, D. P. Green, M. Humphreys, G. Imbens, D. Laitin, T. Madon, L. Nelson, B. A. Nosek, M. Petersen, R. Sedlmayr, J. P. Simmons, U. Simonsohn, and M. Van der Laan. 2014. Promoting transparency in social science research. Science 343:30-31.

Papaioannou, D., A. Sutton, C. Carroll, A. Booth, and R. Wong. 2010. Literature searching for social science systematic reviews: Consideration of a range of search techniques. Health Info. Libr. J. $27: 114-122$.

Penev, T. 2011. Lameness scoring systems for cattle in dairy farms. Agric. Sci. Technol. 3:291-298.

Peters, M. D. J., C. M. Godfrey, H. Khalil, P. McInerney, D. Parker, and C. B. Soares. 2015. Guidance for conducting systematic scoping reviews. Int. J. Evid.-Based Healthc. 13:141-146.

Rao, B. S., R. L. Kherde, and S. V. N. Rao. 1990. A study on the attitude of dairy farmers towards dairy production technologies. Indian J. Anim. Prod. Manag. 6:145-149.

Rehman, T., K. McKemey, C. M. Yates, R. J. Cooke, C. J. Garforth, R. B. Tranter, J. R. Park, and P. T. Dorward. 2007. Identifying and understanding factors influencing the uptake of new technologies on dairy farms in SW England using the theory of reasoned action. Agric. Syst. 94:281-293.

Ritter, C., G. P. Kwong, R. Wolf, C. Pickel, M. Slomp, J. Flaig, S. Mason, C. L. Adams, D. F. Kelton, J. Jansen, J. De Buck, and H. W. Barkema. 2015. Factors associated with participation of Alberta dairy farmers in a voluntary, management-based Johne's disease control program. J. Dairy Sci. 98:7831-7845.

Roccas, S., L. Sagiv, S. H. Schwartz, and A. Knafo. 2002. The Big Five personality factors and personal values. Pers. Soc. Psychol. Bull. 28:789-801.

Rouha-Mulleder, C., C. Iben, E. Wagner, G. Laaha, J. Troxler, and S. Waiblinger. 2009. Relative importance of factors influencing the prevalence of lameness in Austrian cubicle loose-housed dairy cows. Prev. Vet. Med. 92:123-133. 
Santman-Berends, I., M. Buddiger, A. J. G. Smolenaars, C. D. M. Steuten, C. A. J. Roos, A. J. M. Van Erp, and G. Van Schaik. 2014. A multidisciplinary approach to determine factors associated with calf rearing practices and calf mortality in dairy herds. Prev. Vet. Med. 117:375-387.

Saucier, G., and L. R. Goldberg. 2001. Lexical studies of indigenous personality factors: Premises, products, and prospects. J. Pers. 69:847-879.

Scherpenzeel, C. G., S. H. Tijs, I. E. den Uijl, I. M. Santman-Berends, A. G. Velthuis, and T. J. Lam. 2016. Farmers' attitude toward the introduction of selective dry cow therapy. J. Dairy Sci. 99:8259 8266.

Schewe, R. L., J. Kayitsinga, G. A. Contreras, C. Odom, W. A. Coats, P. Durst, E. P. Hovingh, R. O. Martinez, R. Mobley, S. Moore, and R. J. Erskine. 2015. Herd management and social variables associated with bulk tank somatic cell count in dairy herds in the eastern United States. J. Dairy Sci. 98:7650-7665.

Schwarz, N., and G. Bohner. 2001. The construction of attitudes. Pages 436-457 in Intrapersonal Progress (Blackwell Handbook of Social Psychology). Blackwell, Oxford, UK.

Seabrook, M. F. 1972. A study to determine the herdsmans personality on milk yield. Journal of the British Society for Agricultural Labour Science 1:45-59.

Silverlas, C., and I. Blanco-Penedo. 2013. Cryptosporidium spp. in calves and cows from organic and conventional dairy herds. Epidemiol. Infect. 141:529-539.

Tarabla, H. D., and K. Dodd. 1990. Associations between farmers' personal characteristics, management practices and farm performance. Br. Vet. J. 146:157-164.
Toma, L., J. C. Low, B. V. Ahmadi, L. Matthews, and A. W. Stott. 2015. An analysis of cattle farmers' perceptions of drivers and barriers to on-farm control of Escherichia coli O157. Epidemiol. Infect. 143:2355-2366.

Toma, L., A. W. Stott, C. Heffernan, S. Ringrose, and G. J. Gunn 2013. Determinants of biosecurity behaviour of British cattle and sheep farmers-A behavioural economics analysis. Prev. Vet. Med. 108:321-333.

Vaarst, M., and J. T. Sorensen. 2009. Danish dairy farmers' perceptions and attitudes related to calf-management in situations of high versus no calf mortality. Prev. Vet. Med. 89:128-133.

Vande Velde, F., E. Claerebout, V. Cauberghe, L. Hudders, H. Van Loo, J. Vercruysse, and J. Charlier. 2015. Diagnosis before treatment: Identifying dairy farmers' determinants for the adoption of sustainable practices in gastrointestinal nematode control. Vet. Parasitol. 212:308-317.

van den Borne, B. H., J. Jansen, T. J. Lam, and G. van Schaik. 2014. Associations between the decrease in bovine clinical mastitis and changes in dairy farmers' attitude, knowledge, and behavior in the Netherlands. Res. Vet. Sci. 97:226-229.

Waiblinger, S., C. Menke, and G. Coleman. 2002. The relationship between attitudes, personal characteristics and behaviour of stockpeople and subsequent behaviour and production of dairy cows. Appl. Anim. Behav. Sci. 79:195-219.

Wilson, T. D., S. Lindsey, and T. Y. Schooler. 2000. A model of dual attitudes. Psychol. Rev. 107:101-126. 